\title{
The Relationship Between DMFT with Dietary Habits and Body Mass Index in 4-6 YearOld Kindergarten Children in Ahvaz
}

\author{
Sodabeh Amiri ${ }^{*}$, Mahbobeh Rahmani ${ }^{2}$, Masoud Veissi ${ }^{3}$, Morteza Saleki $^{4}$, Mohammadhosein Haghighizadeh ${ }^{5}$ \\ 1-MSC in Nutrition Science. Arak University of Medical Sciences, Arak, Iran. \\ 2- MSc Health Technology Assessment. Arak University of Medical Sciences, Arak, Iran. \\ 3-Postgraduate Student, of Orthodontic. Department of Pediatric Dentistry, School of Dentistry, Ahvaz Jundishapur University of Medical Sciences, \\ Arvand Branch, Ahvaz, Iran. \\ 4- Lecturer of Nutrition Science. Ahvaz Jundishapur University of Medical Sciences, Arvand Branch, Ahvaz, Iran. \\ 5-MSc, Academic Member. Ahvaz Jundishapur University of Medical Sciences, Arvand Branch, Ahvaz, Iran.
}

\section{A B S T R A C T}

Background and Objectives: Considering importance of food habits and possible roles of obesity in tooth decay, the present study was carried out to investigate relationships between dietary habits and body mass index (BMI) withtooth decay in 4-6 years old kindergartenchildrenin Ahwaz, Iran.

Materials and Methods: In this descriptive-analytical study, 359 children were selected randomly from 4-6 year-old children of both sexes from variousregions of Ahvaz, Khuzestan Province, Iran. The project questionnaire includedgeneral and individual information such as gender, age, education and occupation of the parents, economic condition,informationon children andfrequency of feeds of 59 food itemsThe BMIcalculatedandDMFT(decayed, missing, filled surfaces teeth)and erosion were measured. The SPSS Software was used o analyze data.

Results: Frequency and percentage of BMI were differentiated by lean children (37, 10\%), normal weight children (269 children, 75\%) and children with overweight and obesity (53 children, 15\%).Dental caries werefound in 87.3 and erosions in $23.7 \%$ of the children.A significantlypositive correlation was seen between the dental caries index and the BMI $(\mathrm{r}=0.512, P<0.001)$ and dental erosion $(\mathrm{r}=0.141, P=0.007)$. Another significantlypositive correlation was observed between the erosion index and the dental caries index $\mathrm{r}=0.367, P<0.001)$. However, a significantly negative correlation was reported between the erosion index and the serving sizes of meat and egg per month $(\mathrm{r}=-0.112, P=0.034)$. A significantly positive correlation was seen between the erosionandconsumption of chips and puffs $(\mathrm{r}=0.151, P=0.004)$.

Conclusions: Findings of this study have shown that the BMI increases dental caries and erosions.Dental erosion also relationship with increasing consumption of meat and eggs, and increased with the consumption of chips and puff. Dental erosion decreased with increasing mother's age index. According to regression test, BMI had the highest correlation with DMFT index and according to the regression test; the variable DMFT had the highest correlation with the erosion index. With increasing BMI, the amount of dental erosion and dental caries index would increase. There was a significant relationship between the increase in consumption of Chocolatemilk, flavored milk and fats with increased risk of dental caries.

Keywords: Dental caries, Body mass index (BMI), Dental wear, Food habit, Children

\section{Introduction}

Dental caries (decay) is one of the most common and preventable diseases in children. It is a chronic infectious disease that unlike other infectious diseases cannot be stopped by antibiotics. Therefore, the World Health Organization (WHO) has recommended that all countries emphasize on oral health education programs. Plans of dental care systems should be used to identify risk factors that directly affect development of dental decay and control or prevent dental decay by adopting appropriate guidelines based 
on the principles of health promotion(1).In tooth decays, produced acids from the metabolism of bacteria that fermentcarbohydratesresult in destruction of the enamel and tooth structure. Despite the decline in dental caries from $75 \%$ in 1970 to $42 \%$ in 1999-2004, dental caries are still a highly-spread infectious disease, especially in developing countries such as Iran (2). Dental problems in childhood arestarted at the level of food eatingwhich effectchildren development, speaking and communicating with others. Although investigation of the relationships between obesity and caries requires comprehensive research studies, the major etiology includes factors that root in lifestyle changes such as 1)negative nutritional changes, 2)decreases physical activity patterns, and 3).increasesin consumption of fast foods. Increased consumption of fermentable carbohydrates, contributes to obesity and caries with unpleasant consequences such as loss of permanent teeth (3).Research on dental caries have mainly shown effects of food intakes on dental surfaces(4). Tooth decay is a multiple caustic disease, including food properties (dental adhesion), individual factors (plaque microbial composition, salivary characteristics and tooth structure differences) andsocioeconomic factors(5). Although water flora decreasesseverity of decay in some populations, the link between fermented carbohydrate consumption and tooth decay is generally known(5).In several studies, the prevalence of dental caries in preschool children is considered $12.3-76.1 \%(2,6)$. Based on study in Iran, the prevalence of dental caries is high in preschool children and varies $31.64-83.7 \%$ (7). Studies on 6-year-old childrenin in Ahwaz have shown the average DMFTas 36.3 (girls, 3.40;boys, 3.30)(8).

Tooth decay can be a source of oxidative stress. Oxidative damage can cause inflammation in the body for many years or even decades, resulting in production of inflammatory hormones and chemicals. These chemicals and chemicalsactivategenesof fat storage and, at the same time, silence genes which decreaseinflammation, creating health risks. Therefore, weakness of the immune system is one of the major causes of chronic degenerative diseases, including, diabetes, heart diseases and obesity(9). The triangular relationship between sugars, dental caries and obesity needs further investigation.(9).In a study by Alm et al. on subjects at ages of 3,6,15 and
20 year old to, assess effects of BMI on prevalence of dental caries, it was shown that overweight and obese adolescents and youth have a higher prevalence rate of dental carries, compared to that normal-weight adolescents have.(10). Recent studies in Sweden have shown a positive correlation between the tooth decay and the body mass index (BMI) due to the nutritional behaviors, especially consumption of fast foods,lead to obesity. Meanwhile, chronic malnutrition, especially in the first years of life, has increased the potential dental caries. Evidence have shownthat tooth decay is associated with high and low BMI(11).Overweight and obesity have been shownin adolescents with higher DMFT indices(12). Erosion, as a losing advanced irreversible tooth decay, is due to a chemical process by soluble acids that does not include effects of bacteria(13).

During the erosion process, enamel or dentin, is dissolved and degraded by direct and constant contact with acids. Chemical erosion of the teeth is different from the damage caused due to the acids produced by decay bacteria. Unlike tooth decay, erosion can affect all tooth surfaces and cause tooth enamel loss. Finally, Dental caries that remains uncoveredcausing the teeth sensitive to hot and cold foods, toothache, tooth decay and aesthetic problems.An effective dental control depends largely on understanding causes and symptoms of the clinical diseases. an effective prevention of the tooth erosion involves measures that can prevent or decrease direct contact with acids (14). During epidemiological studiesreport the prevalence of dental erosion as $83-0.6 \%$. In most of these studies, more than $30 \%$ of children have at least a tooth with erosion(2, 15).In study Garcia, prevalence of dental erosion in Brazil was reported as 51.6\% in 2016.(15), while prevalence of dental erosion in children and adults were 34.1 and $31.8 \%$, respectively(14). Based on the studies in Iran, prevalence of dental caries in preschool children is high and varies31.64-83.7\%(7).According to the highlighted results, the present study wascarried out to investigate relationships between the dietary habits and BMIand the dental erosions in 4-6 year-old children in Ahwaz, Iran. Using results of this study, good health plans and therapeutic and educational programs can be achieved to improve the oral health in the target group. 


\section{Materials and Methods}

The present study is a descriptive-demographic design that the target group was calculated using the statistical formulas of the sample size, according to similar studies in this field.In Feb 2012,135 kindergartens(private and public) in eight areas in Ahvaz, wereRandomly(based on couples classroom numbers)clustered and 10 kindergartens were selected359 specimens of 4-6 year old child from both sexes were selected according to the list of classes, in a way that half of the children in this age were randomly selected for the study.Entry criteria included 4-6 year-old kindergarten children of both sexes and exit criteria have been considered voluntary.After obtaining written consent from parents of children to participate in the study, we measured the height and weight of children in kindergarten. Weight and height were measured. The BMI was calculated by dividing the weight $(\mathrm{kg})$ by height (square meter). Overweight and obesity were defined as percentiles of $94-85$ and $\leq 95$, respectively. BMIs were defined separately for age and sex, standard percentiles of the children were used from the whose new reference MGRS(5).

Data collection methods: A general and individual information questionnaire, including gender, age, education and occupation of the parents' economic conditions,information on children were designed.Foodfrequency questionnaire including 59 food items(vegetables, fruits, roasted corn, dairy, chocolate and flavored milks, all types of meat, eggs ,nuts and seeds)with positive or negative effects on dental health status by determining dietary habits was given to parents for completion and the forms completed by kindergarten managers were collected. This questionnaire through a pre-test was assessed thevalidity of the food frequency questionnaire (alpha Cronbach's coefficient of $80 \%$ ) in astudy byMohtadinia and his colleagues (2).Anthropometric measurements have been analyzed to measure BMI. Clinical examinations were performed to measure the DMFT index and erosion status(based on examination form Smith and Knight), which samples were invited to dentistry pediatrician for dental examinations. Erosion and DMFT index (decayed, missing, filled surfaces teeth) were measured. The evaluation of decay status from the DMFT index has been used in accordance with WHO criteria(16).
Statistical: To determine the correlation between quantitative variables, Pearson correlation coefficient test, $\mathrm{T}$ test and Chi-square test were used. Regression analysis was used to compare the variables statistical analysiswas performed using SPSS $_{16}$ software. $\mathrm{A} P$ valueless than 0.05 was considered as significant.

\section{Results}

Based on the results, $75 \%$ of children included normal weight and nearly $15 \%$ included overweight and obesity (Table 1).Dental caries was not found in $44(12.3 \%)$ of the children while found in 315 children. Dental decay was not observed in 268 children $(74.7 \%)$ (Table 2).

Table 1.Frequency and percentage of the body mass index (BMI)

\begin{tabular}{lcc}
\hline Anthropometric index & Abundance & Percentage \\
\hline Thin & 37 & 10.31 \\
Normal & 269 & 74.65 \\
Overweight/Obese & 53 & 14.76 \\
Total & 359 & 100 \\
\hline
\end{tabular}

Table 2.Frequencies of dental caries index and dental wear

\begin{tabular}{lccccc}
\hline & \multicolumn{2}{c}{ With } & \multicolumn{2}{c}{ Without } & Total \\
\cline { 2 - 6 } & Percentage & Abundance & Percentage & Abundance & Abundance \\
\hline Erosion & 23.7 & 85 & 74.7 & 268 & 359 \\
DMFT & 87.3 & 315 & 12.3 & 44 & 359 \\
\hline
\end{tabular}

A significant difference was seen between the mean DMFT index of boys $(2.33 \pm 2.87)$ and that of girls $(1.97 \pm 2.41)$, which was statistically significant in terms of sex.Furthermore, a significant difference was observedin resistancetodental decay between the boys $(0.53 \pm 0.36)$ and girls $(0.42 \pm 0.2)$. No significant differences were seen between the BMI ofboys and girls (Table 3).

Table 3.Descriptive statistics ofDMFT, tooth erosion and BMI,separated by sex

\begin{tabular}{llccc}
\hline Variable & Sex & Number & SD \pm mean & P value \\
\hline DMFT & Boy & 161 & $2.86 \pm 2.33$ & 0.048 \\
& Girl & 198 & $2.41 \pm 1.97$ & \\
Erosion & Boy & 161 & $0.36 \pm 0.53$ & 0.001 \\
& Girl & 198 & $0.2 \pm 0.42$ & \\
BMI & Boy & 161 & $15.83 \pm 2.18$ & 0.304 \\
& Girl & 198 & $16.09 \pm 2.48$ & \\
\hline
\end{tabular}


Significantly positive correlations were reported between the dental caries index and the BMI $(\mathrm{r}=0.512, \quad P<0.001)$, the dental caries and the $\operatorname{BMI}(\mathrm{r}=0.141, \quad P=0.007)$, and betweenthe DMFT index and the erosion index $(r=0.367, P<0.001)$ (Table 4).

Table 4.Correlations between the DMFT,erosion and BMIindices

\begin{tabular}{llccc}
\hline $\begin{array}{l}\text { Dependent } \\
\text { variable }\end{array}$ & & BMI & DMFT & Erosion \\
\hline DMFT & Pearson correlation & 0.512 & 1.000 & 0.367 \\
& $P($ value $)$ & 0.000 & 0.000 & 0.000 \\
& Number & 359 & 359 & 359 \\
Erosion & Pearson correlation & 0.141 & 0.367 & 1.000 \\
& $P($ value $)$ & 0.007 & 0.000 & \\
& Number & 359 & 359 & 359 \\
\hline
\end{tabular}

A significantly positive correlation was detected between the dental caries index and the consumption of cocoa and flavored milks $(\mathrm{r}=0.13, P=0.016)$ and a significantly negative correlation between the
DMFT index andthe meat and eggconsumptions $(\mathrm{r}=$ $0.11, P=0.034$. No correlations were observed between the indices of tooth decay and the consumption of raw and cooked vegetables, fruits, roasted maize, dairies, legumes and seeds. A significantly positive correlation was reported between the index of dental caries and the fat intake during the month $(\mathrm{r}=0.12, \quad P=0.027)$. However, relationships between the frequencies of fatintakecan be indirect due to increases in BMI, overweight orobesity. Correlations between the DMFT and the erosion indices and food itemsareshown in Table 5.

A significantly positive correlation was seen between the index of dental caries and the consumption of nuts in boys $(\mathrm{r}=0.17, P=0.031)$ and consumption of chocolate and flavored milks in girls $(\mathrm{r}=0.18, P=0.011)$. Moreover, a significantly negative correlation was observed between the erosion index and the consumption of nuts in boys ( $\mathrm{r}=-0.16$, $P=0.043$ ) (Table 6).

Table 5.Correlations between the DMFT andthe erosion indices ofvegetables, fruits, roasted corns, dairies, milks, meats, eggs,nuts, seeds, fruit juices, dried fruits, ice creams, breads, biscuits, cakes, chips , puffs, candies, high-sugar foods, ordinary gums and fats

\begin{tabular}{|c|c|c|c|c|}
\hline \multirow[t]{2}{*}{ The dependent variable } & \multicolumn{2}{|c|}{$\begin{array}{c}\text { DMFT } \\
(\mathrm{N}=359) \\
\end{array}$} & \multicolumn{2}{|l|}{$\begin{array}{c}\text { Erosion } \\
(\mathrm{N}=359)\end{array}$} \\
\hline & Pearson correlation & $\mathrm{p}$ (value) & Pearson correlation & $\mathrm{p}$ (value) \\
\hline fats & 0.12 & 0.027 & 0.04 & 0.495 \\
\hline Gazellitol gum & -0.05 & 0.391 & -0.06 & 0.294 \\
\hline Chewing gum & 0.001 & 0.978 & -0.001 & 0.982 \\
\hline High sugar foods & -0.05 & 0.376 & -0.06 & 0.260 \\
\hline Candy & -0.03 & 0.628 & 0.07 & 0.177 \\
\hline Chips and puffs & 0.05 & 0.391 & 0.151 & 0.004 \\
\hline Different types of cookies, crackers and cakes & 0.005 & 0.924 & 0.03 & 0.574 \\
\hline bread & -0.02 & 0.719 & 0.07 & 0.160 \\
\hline Ice cream & -0.01 & 0.844 & 0.03 & 0.573 \\
\hline Dried fruits & -0.01 & 0.856 & -0.002 & 0.976 \\
\hline Fruit juices and compote and carbonated beverages & -0.01 & 0.881 & -0.02 & 0.710 \\
\hline nuts & 0.05 & 0.329 & -0.085 & 0.109 \\
\hline beans & -0.02 & 0.736 & 0.059 & 0.263 \\
\hline Meats and eggs & -0.013 & 0.800 & -0.11 & 0.034 \\
\hline Cocoa and Flavored Milk & 0.13 & 0.016 & -0.006 & 0.914 \\
\hline dairy & 0.003 & 0.955 & -0.039 & 0.461 \\
\hline pop corn & -0.02 & 0.717 & -0.043 & 0.416 \\
\hline Fruitage & -0.05 & 0.362 & 0.041 & 0.440 \\
\hline Raw and cooked vegetables & -0.05 & 0.369 & -0.023 & 0.666 \\
\hline
\end{tabular}


Sodabeh Amiri, et al: The relationship between dental caries with cietary habits

Table 6.Correlations between the DMFT andthe erosion indicesof,vegetables, fruits, roasted corns, dairies, chocolates and flavored milks, meats, eggs, nuts and seedsseparated by sexes

\begin{tabular}{|c|c|c|c|c|c|c|c|c|c|c|}
\hline Sex & Variation & & Nut & Bean & $\begin{array}{l}\text { Type of meat } \\
\text { and egg }\end{array}$ & $\begin{array}{l}\text { Chocolate and } \\
\text { flavored milk }\end{array}$ & Dairy & Pop corn & Fruitage & $\begin{array}{c}\text { Raw and } \\
\text { cooked vegetables }\end{array}$ \\
\hline \multirow{6}{*}{ Boy } & DMFT & Pearson correlation & 0.17 & -0.02 & -0.02 & 0.06 & -0.07 & 0.05 & -0.11 & 0.01 \\
\hline & & Number & 161 & 161 & 161 & 161 & 161 & 161 & 161 & 161 \\
\hline & & $P$ value & 0.031 & 0.810 & 0.756 & 0.472 & 0.352 & 0.498 & 0.150 & 0.876 \\
\hline & & Pearson correlation & -0.16 & 0.13 & -0.12 & -0.02 & -0.09 & -0.12 & 0.04 & -0.09 \\
\hline & Erosion & Number & 161 & 161 & 161 & 161 & 161 & 161 & 161 & 161 \\
\hline & & $P$ value & 0.043 & 0.092 & 0.128 & 0.846 & 0.269 & 0.139 & 0.631 & 0.266 \\
\hline \multirow{6}{*}{ Girl } & & Pearson correlation & -0.06 & -0.03 & -0.01 & 0.18 & 0.07 & -0.05 & 0.00 & -0.08 \\
\hline & DMFT & Number & 198 & 198 & 198 & 198 & 198 & 198 & 198 & 198 \\
\hline & & $P$ value & 0.444 & 0.687 & 0.895 & 0.011 & 0.358 & 0.507 & 0.969 & 0.258 \\
\hline & & Pearson correlation & 0.03 & -0.03 & -0.12 & -0.01 & 0.00 & 0.00 & 0.04 & 0.07 \\
\hline & Erosion & Number & 198 & 198 & 198 & 198 & 198 & 198 & 198 & 198 \\
\hline & & $P$ value & 0.731 & 0.697 & 0.094 & 0.929 & 0.971 & 0.977 & 0.606 & 0.336 \\
\hline
\end{tabular}

\section{Discussion}

In this study, the highest mean DMFT included mean \pm SD of5.00 $\pm 2.65(n=3)$, while in study of Mohtadinia et al. (2011) on 202 3-12 years old children referred to Dental Clinic of Tabriz University of Medical Sciences in 2009, meanDMFT included3.80 $\pm 7.61(2)$. In shafiei et al. (2015) study on 1482 children aged 3-6 years old in kindergartens and preschool centers of Kerman (2009-2010), DMFT index for 4-year-old children included 3.09 \pm 2.31 and for5-year-old children included 3.25 \pm 2.99 (17), supporting results from the current study. In the current study, a significant positive correlation was seen between the erosion and BMI $(r=0.141$, $P=0.007)$, and the index of dental caries and BMI $(\mathrm{r}=0.512, \quad P<0.001)$. Similarly, Shafieiet al. (2015) showed a significant positive correlation of $P<0.05(17)$.However, other studies could not show any relationships between the dental caries and BMI(2). Yan-Fang Renreported increases in BMI, while the number of dental caries increased. He also reported that obese children wereat greater risksof developing tooth erosions (14). In the present study, a significant correlation was observed between the BMI and dental cariesindex. Therefore, prevention of obesity and overweighting in children and implementation of healthy child programs by the Ministry of Health are appropriate strategies to decrease erosionsand DMFD as well as costs of treatment.

In the current study, no correlation was reported between the frequency of brushing, DMFT and erosion. In contrast, studies by Faezi et al.(18) and Taani on 2083 cases reported ,that increased number of brushing decreased DMFT. In Guadagni study, a significant correlation was seen between the number of brushing and DMFT level (2).Therefore, lack of relationships in the present study does not deny the importance of health care for mouth and teeth.Clancy et al.(17) and Nurelhuda et al.(3) reported that children with highereducated mothers consumed more sugar-free foods and had ,less DMFT. In the present study, however,theparent education did not affect the DMFT. Therefore, in addition to their educationallevel, people should plan to increase their health literacy.In this study, the erosion index (dependent variable) and independent variables included DMFT, chips,puffs, meats, eggs and sex. The DMFT variable included the highest correlation with the erosion index. Thus, protein foods protect teeth against erosions andfoods with adhesionto enamels and high-salt contents cause erosions.In this study, relationships between the independent variables (BMI, chocolate milk,flavorsandfats) and tooth erosion index (dependent variable)werenot significant, but a positive relationship was observed, with the highest percentage of fats (37\%). The BMI showed the highest correlation with dental caries index.

The World Health Organization (WHO) recommends that all countries emphasize on oral health education programs.Planning in dental care systems should identify risk factors that directly contribute to decayandcontrolprevent itsdeterioration using appropriate strategies.In the current study, 
DMFT included the highestpositive correlation with the erosion index. Dental anesthesia prevention is an important step in preventing tooth erosions. Moreover, it is possible to establish health-care facilities for the prevention of obesity and overweight and promotion of oral and dental hygienes in this target group.Dental specialists, in collaboration with nutritionists, play an important role in describing proper diet plans.The best age group for developing healthy eating habits is childhood because children can correctlylearn healthy eating habits and memorize them for the future.

\section{Conclusion}

According to the results of this study, preventing overweight and obesity is an important strategy for preventing tooth erosion and abrasion. Considering that the dmft variable had the most positive correlation with the erosion index, dental anesthesia prevention is also an important step in preventing tooth erosion. In addition, it is possible to plan healthcare facilities to prevent obesity and overweight and promote oral and dental hygiene in this target group.

\section{Acknowledgement}

Thanks and appreciation to the Vice-Chancellor of Research at Arvand International School and the Jundishapour Medical Sciences University, the Ahvaz Welfare Office, the kindergarten and mothers who help us in this study.

\section{Financial disclosure}

The author declares no conflict of interest.

\section{References}

1. Mehrabkhani M, Ajami B, Khademi M, Arastoo S. Evaluating Risk Factors of Dental Caries in Children under 6-Years-Old Supported by Welfare Organization of Mashhad in 2012. Journal of Mashhad Dental School. 2014;38(3):257-66.

2. Mohtadinia $\mathbf{J}$ EH, parizan S, Kalejahi $\mathrm{P}$ N. The relationship between dental caries and body mass index and food habits in children referred to dentistry clinic of Tabriz university of medical sciences. Yafteh. 2011;12(3).

3. Nuroloyuni $\mathrm{S}$ ea. "The relationship between BMI and dental caries of permanent first molars in children 6-12 years of Ardabil" Ardabil Univercity of Medical Sciences.2013.
4. Oskuee SS, Alizadeh Oskuee P, Mohammadi N, Kimiaie S, Vatandoost H. The Relationship between Snacks and Sweet Drinks Consumption at School Times with First Molar Cavities Level. J Ardabil Univ Med Sci 2007, 7(1): 46-51

5. Goodson JM, Tavares M, Wang X, Niederman R, Cugini M, Hasturk $\mathrm{H}$, et al. Obesity and dental decay: inference on the role of dietary sugar. PLoS One. 2013;8(10):e74461.

6. Granville-Garcia AF, Menezes VAd, Lira PId, Ferreira JM, Leite-Cavalcanti A. Obesity and dental caries among preschool children in Brazil. Revista de Salud Pública. 2008;10:788-95.

7. Afroughi S, Faghihzadeh S, Khaledi M, Motlagh MG. Effects of adjacent teeth on caries status of a deciduous tooth in 3-5 years-old children. Armaghane Danesh Bimonthly Journal. 2010;15(3):253-61.

8. Basir L ea. Comparison of oral hygiene and DMFT among 6 year old boys and girls in Ahwaz city in 79 . Jundishapur Sci Med J. 2006;5(2).

9. H. PI. Dental plaque. The Journal of Islamic Dental Associationof IRAN (JIDA). 1991;5(1).

10. Alm A, Isaksson H, Fahraeus C, Koch G, AnderssonGare B, Nilsson M, et al. BMI status in Swedish children and young adults in relation to caries prevalence. Swed Dent J. 2011;35(1):1-8.

11. Hooley M, Skouteris H, Boganin C, Satur J, Kilpatrick $\mathrm{N}$. Body mass index and dental caries in children and adolescents: a systematic review of literature published 2004 to 2011. Systematic reviews. 2012;1(1):57.

12. Tripathi S, Kiran K, Kamala B. Relationship between obesity and dental caries in children-A preliminary study. J Int Oral Health. 2010;2(4):65-72.

13. Li H, Zou Y, Ding G. Dietary factors associated with dental erosion: a meta-analysis. PLoS One. 2012;7(8):e42626.

14. Yan-Fang Ren D. Dental erosion: etiology, diagnosis and prevention. ADA: The academy of dental therapeutic and stomatology p. 2011;76.

15. Murakami C, Tello G, Abanto J, Oliveira LB, Bonini GC, Bönecker M. Trends in the prevalence of erosive tooth wear in Brazilian preschool children. Int $\mathbf{J}$ Paediatr Dent. 2016;26(1):60-5.

16. Hiremath S. Textbook of preventive and community dentistry: Elsevier India; 2011.

17. Bafti LS, Hashemipour MA, Poureslami H, Hoseinian Z. Relationship between body mass index and tooth decay in a population of 3-6-year-old children in Iran. Int J Dent. 2015;2015:126530

18. Faezi M, Farhadi S, NikKerdar H. Correlation between $\mathrm{dmft}$, diet and social factors in primary school children of Tehran-Iran in 2009-2010. Journal of Mashhad Dental School. 2012;36(2):141-8. 